\title{
Could successful cryoballoon ablation of paroxysmal atrial fibrillation prevent progressive left atrial remodeling?
}

\author{
Tamás Erdei ${ }^{1,2^{*}}$, Mónika Dénes ${ }^{2}$, Attila Kardos ${ }^{2}$, Attila Mihálcz ${ }^{2}$, Csaba Földesi $^{2}$, András Temesvári ${ }^{2}$ and
} Mária Lengyel ${ }^{2}$

\begin{abstract}
Background: Radiofrequency catheter ablation of atrial fibrillation (AF) has been proved to be effective and to prevent progressive left atrial (LA) remodeling. Cryoballoon catheter ablation (CCA), using a different energy source, was developed to simplify the ablation procedure. Our hypothesis was that successful CCA can also prevent progressive LA remodeling.

Methods: 36 patients selected for their first CCA because of nonvalvular paroxysmal AF had echocardiography before and 3, 6 and 12 months after CCA. LA diameters, volumes (LAV) and LA volume index (LAVI) were evaluated. LA function was assessed by: early diastolic velocities of the mitral annulus ( $\left(\mathrm{a}_{\mathrm{sept}}, \mathrm{Aa} \mathrm{a}_{\text {lat }}\right.$ ), LA filling fraction (LAFF), LA emptying fraction (LAEF) and the systolic fraction of pulmonary venous flow (PVSF). Detailed left ventricular diastolic function assessment was also performed.

Results: Excluding recurrences in the first 3-month blanking period, the clinical success rate was $64 \%$. During oneyear of follow-up, recurrent atrial arrhythmia was found in 21 patients (58\%). In the recurrent group at 12 months after ablation, minimal LAV (38 \pm 19 to $44 \pm 20 \mathrm{ml} ; p<0.05)$, maximal LAV (73 \pm 23 to $81 \pm 24 \mathrm{ml} ; p<0.05)$, LAVI (35 \pm 10 to $39 \pm 11 \mathrm{ml} / \mathrm{m}^{2} ; p=0.01$ ) and the maximal LA longitudinal diameter ( $55 \pm 5$ to $59 \pm 6 \mathrm{~mm} ; p<0.01$ ) had all increased. PVSF (58 \pm 9 to $50 \pm 10 \% ; p=0.01$ ) and LAFF (36 \pm 7 to $33 \pm 8 \% ; p=0.03$ ) had decreased. In contrast, after successful cryoballoon ablation LA size had not increased and LA function had not declined. In the recurrent group LAEF was significantly lower at baseline and at follow-up visits.

Conclusions: In patients whose paroxysmal atrial fibrillation recurred within one year after cryoballoon catheter ablation left atrial size had increased and left atrial function had declined. In contrast, successful cryoballoon catheter ablation prevented progressive left atrial remodeling.
\end{abstract}

Keywords: Paroxysmal atrial fibrillation, Cryoballoon catheter ablation, Echocardiography, Left atrial remodeling, Left atrial size, Left atrial function

\section{Background}

The relationship between left atrial (LA) dilatation and atrial fibrillation (AF) has been widely accepted for a long time [1]. Electrophysiological, structural and functional atrial remodeling have been observed in patients with $\mathrm{AF}$, and it has been shown that normal myocardial tissue is often replaced with fibrosis [2]. Dilated left

\footnotetext{
* Correspondence: dr.tamas.erdei@gmail.com

${ }^{1}$ Semmelweis University, School of Ph.D. Studies, Budapest, Üllői út 26 H1085, Hungary

Full list of author information is available at the end of the article
}

atrium predict later cardiovascular events [3]. Catheter ablation of atrial fibrillation has been established as a therapeutic option for patients with symptomatic, drugresistant AF $[4,5]$.

Radiofrequency catheter ablation (RFCA) can affect left atrial size and function either from the scar caused by the ablation or from reverse atrial remodeling following conversion to normal sinus rhythm. After successful RFCA of atrial fibrillation, LA size has been found to decrease and LA function and left ventricular diastolic function to improve; the process has been called 'reverse
C Biomed Central

(C) 2012 Erdei et al; licensee BioMed Central Ltd. This is an Open Access article distributed under the terms of the Creative Commons Attribution License (http://creativecommons.org/licenses/by/2.0), which permits unrestricted use, distribution, and reproduction in any medium, provided the original work is properly cited. 
LA remodeling'. In contrast, after an unsuccessful catheter ablation, opposite changes were observed [6-13] and confirmed by a meta-analysis [14].

Cryothermal energy is an alternative energy source that has been developed to overcome some of the disadvantages of RFCA. Cryoenergy offers increased catheter stability, less endothelial disruption with lower thromboembolic risk, and minimal tissue contraction with healing, less generation of inhomogeneous lesions, less oesophageal damage and fewer pulmonary vein stenoses. Balloon-based cryo-technology potentially offers a simpler and faster means of isolating the pulmonary veins that, theoretically, relies less on the dexterity of the operator and causes less scar in the left atrium. Previous studies suggest this is a safe and feasible approach with a similar success rate in patients with paroxysmal AF (PAF) to radiofrequency catheter ablation [15].

Left atrial remodeling has not been examined in the previous studies which used cryoballoon catheter ablation of patients with AF $[15,16]$. Our hypothesis was that successful cryoballoon catheter ablation of patients with paroxysmal AF similarly to RFCA can also prevent progressive LA remodeling.

\section{Methods}

\section{Patients}

36 consecutive patients with recurrent, symptomatic, nonvalvular PAF were enrolled in the study between June 2008 and July 2009. All had failed to respond antiarrhythmic (propafenone, or amiodarone, or sotalol) or beta blocker therapy. They underwent their first catheter ablation by the cryoballoon technique.

The study was carried out in compliance with the Helsinki Declaration and was approved by the Regional and Institutional Scientific and Research Ethics Committee of the Semmelweis University Budapest (reference number: TUKEB 70/2008). All patients gave written informed consent before participating in the study.

\section{Cryoballoon ablation}

As described in our previous report [17], all patients were treated with a double lumen cryoballoon (Arctic front, Cryocath, Montreal, Quebec), after local anaesthesia and under conscious sedation using boluses of midazolam and fentanyl. At first a decapolar electrophysiological catheter (Bard Electrophysiology Inc., Lowell, MA, USA) was placed in the coronary sinus through the right jugular vein, and a diagnostic quadripolar electrophysiological catheter was introduced through the right femoral vein and positioned in the right ventricle. An intracardiac echocardiography catheter (Acunave, Acuson, Mountain View, CA, USA) was introduced through the left femoral vein and positioned in the right atrium, in order to ensure safe transseptal approach. After the intracardiac echocardiography-guided single posterior transseptal puncture, a circular mapping catheter (Lasso catheter, PV Orbiter, Bard) was advanced and positioned in the antrum of each pulmonary vein to record the presence of pulmonary vein potentials. After registration, the $8 \mathrm{~F}$ sheath was exchanged for a $14 \mathrm{~F}$ steerable sheath, and the mapping catheter was exchanged for a $28 \mathrm{~mm}$ balloon catheter and positioned over an exchange wire to occlude the ostium of each pulmonary vein. At least two 5-minute cryo applications per vein were given to each vein, during using continuous phrenic nerve stimulation when freezing the ostium of the right superior pulmonary vein.

\section{Study protocol}

Antiarrhythmic drugs were stopped 5 half-lives before the ablation, and were not continued afterwards. Oral anticoagulation was before and after ablation, according to the CHADS2-score based on the valid guideline [18].

Comprehensive transthoracic echocardiographic examinations were performed in all patients during sinus rhythm before, and 3, 6 and 12 months after cryoballoon catheter ablation. Transoesophageal echocardiography was performed in all patients before catheter ablation, to exclude left atrial and left atrial appendage thrombus. Transthoracic and transoesophageal echocardiography were performed within 24 hours of each other.

After the ablation, follow-up examinations at 1, 3, 6 and 12 months included clinical history and examination, ECG and 24-hour Holter ECG. A 10-day transtelephonic ECG was performed before the 3-month, 6month and 12-month follow-up visits.

\section{Definition of success}

Based on the definition of the Expert Consensus Statement on Catheter and Surgical Ablation of Atrial Fibrillation [4], cryoballoon catheter ablation was considered to be clinically successful, if after the initial 3-month blanking period-a time interval during which success is not evaluated-recurrent atrial arrhythmia was not recognized on clinical, or ECG or Holter ECG, or transtelephonic ECG examinations.

In order to evaluate the effect of all episodes of recurrent arrhythmia, recurrences in the blanking period were also taken into account for the final analysis. So the patients were divided into recurrent and arrhythmiafree (AF-free) groups. The recurrent group was defined as patients with recurrent atrial arrhythmia at any time during the follow-up.

\section{Echocardiography}

Transthoracic echocardiography was performed with a General Electric Vivid S6 machine (General Electric, Milwaukee, WI, USA). 
Left ventricular (LV) global systolic function was assessed by ejection fraction (EF) evaluated by the modified biplane Simpson's rule. LV longitudinal systolic function was assessed by septal and lateral systolic velocities of the mitral annulus $\left(\mathrm{Sa}_{\text {sept }}, \mathrm{Sa}_{\text {lat }}\right)$ using pulsedwave tissue Doppler echocardiography (TDE).

In order to evaluate LA remodeling LA size and LA function were evaluated before and after ablation. LA volumes were calculated by two-dimensional echocardiography by the biplane area-length method. Maximal LA volume $\left(L A V_{\max }\right)$ was obtained at left ventricular end-systole, just before mitral valve opening. Minimal LA volume $\left(\mathrm{LAV}_{\min }\right)$ was determined at left ventricular end-diastole. LA areas $\left(A_{1}, A_{2}\right)$ and superoinferior longitudinal diameters were measured from apical 4- and 2chamber views. LA volumes were calculated by the following formula [19]: $\mathrm{LAV}=8 / 3 \pi^{*} \mathrm{~A}_{1}{ }^{*} \mathrm{~A}_{2} / \mathrm{L}=$ $0.85^{*} \mathrm{~A}_{1}{ }^{*} \mathrm{~A}_{2} / \mathrm{L}$, where $\mathrm{L}$ is the shorter superoinferior diameter of the LA. LA volume index (LAVI) was calculated by dividing maximal LA volume by the body surface area (calculated by the Dubois formula, using body height and weight).

The evaluation of LA function by echocardiography is not standardized; different methods have been used to assess LA function in research and in clinical practice $[20,21]$. The left atrium serves multiple functions, acts as a reservoir during left ventricular systole; as a conduit for blood transiting from the pulmonary veins to the LV during early diastole and as an active contractile pump that augments LV ventricular filling in late diastole.

In the present study four TTE methods were used in the assessment of LA function.

LA booster pump (contractile) function was assessed by:

a) the LA filling fraction (LAFF) which is the ratio of the velocity time integral (VTI) of the late diastolic A wave velocity of mitral inflow to the VTI of the early and late diastolic velocities of mitral inflow (LAFF = $\mathrm{VTI}_{\mathrm{A}} / \mathrm{VTI}_{\mathrm{E}+\mathrm{A}}$ ) and

b) septal and lateral velocities of the mitral annulus during atrial contraction $\left(\mathrm{Aa}_{\text {sept }}, \mathrm{Aa}_{\mathrm{lat}}\right)$, measured by pulsed-wave TDE.

LA reservoir function was assessed by:

a) LA total emptying fraction $\left(\mathrm{LAEF}=\left(\mathrm{LAV}_{\max }-\mathrm{LAV}-\right.\right.$ $\left.\min ) / L^{\prime} V_{\max }\right)$ and

b) the systolic fraction of pulmonary venous flow $\left(\mathrm{PVSF}=\mathrm{VTI}_{\mathrm{S}} / \mathrm{VTI}_{\mathrm{S}+\mathrm{D}}\right)$. Pulmonary venous flow was measured within right upper pulmonary vein.

More recent methods of evaluating LA function, such as colour-coded tissue-Doppler based strain and strainrate and two-dimensional speckle-tracking based strain and strain rate were not available in our institute during the study period.
In the detailed evaluation of left ventricular diastolic dysfunction, we used the methods described in recent recommendations $[22,23]$. Septal and lateral early diastolic velocities of the mitral annulus $\left(\mathrm{Ea}_{\text {sept }}, \mathrm{Ea}_{\text {lat }}\right)$ were measured by TDE, which characterize left ventricular relaxation. In the assessment of mean left ventricular filling pressure E/Ea ratios were calculated, using both the lateral, septal and average Ea velocity. Early (E) and late diastolic (A) velocities of mitral inflow, and deceleration time (DT) were measured by pulsed wave Doppler echocardiography, and E/A ratio was calculated. Systolic (S) and diastolic (D) velocities of pulmonary venous flow were measured and S/D ratio was also calculated.

\section{Statistical analysis}

Data are shown as mean \pm standard deviation (SD) (95\% confidence interval). Unpaired $t$-test was used to compare means of continuous variables between unrelated groups. Chi-square analysis was used to compare patient group characteristics with discrete variables. Paired-sample Student's $t$-test was used to evaluate changes in echocardiographic parameters of LA size and function and of LV diastolic function during the follow-up period within groups. A $p<0.05$ was considered statistically significant for all calculations. Statistical analysis was performed using SPSS (Statistical Software for Social Sciences) version 13.0.

\section{Results and discussion \\ Procedural outcome}

The clinical success rate, as it was defined previously with no recurrence after the 3-month blanking period [4], was 23 out of 36 patients (64\%). Repeat ablation had not been performed during the first year follow-up.

15 patients were totally free of arrhythmias throughout the first 12 months of follow-up (the AF-free group). The other 21 patients (the recurrent group) experienced some recurrence of atrial arrhythmias. Only early (within 3 months after treatment) recurrence in 8 , only between 3 and 12 months after treatment recurrence in 4 , both early and 3 to 12 months recurrences in 9 patients were detected.

\section{Baseline characteristics \\ Baseline clinical characteristics}

36 consecutive patients were enrolled in the study; there were 26 males and the mean age was $57.4 \pm 8.9$ years. The most frequent symptom was palpitation; signs or symptoms of congestive heart failure were not present. 27 patients $(75 \%)$ had hypertension. The average time period from the first recognition of AF was $6.7 \pm 7.3$ years (range 0.5-20). 
In patients who later developed a recurrence (recurrent group), had a longer duration of atrial fibrillation $(8.8 \pm 8.7$ vs $3.8 \pm 3.3$ years, $p<0.05)$ before cryoballoon catheter ablation. At baseline, patients' age, gender, prevalence of concomitant diseases such as hypertension, diabetes mellitus, hyperlipidemia and obesity were not significantly different between the recurrent and AF-free groups (Table 1).

\section{Baseline echocardiographic characteristics}

Left ventricular EF was $63 \pm 5 \%$ (55-72\%). Left ventricular and left atrial dimensions, and left atrial functional parameters, TDE parameters of LV diastolic dysfunction and normal values from the literature [19,23-25] are shown in Table 1.

Septal and lateral early diastolic velocities of the mitral annulus (Easept, Ealat), E/Ea ratios, LA size and LA

Table 1 Baseline clinical and echocardiographic characteristics

\begin{tabular}{|c|c|c|c|c|c|}
\hline & $\begin{array}{c}\text { Total study population ( } \mathrm{n} \\
=36 \text { ) }\end{array}$ & $\begin{array}{l}\text { Recurrent group }(\mathrm{n}= \\
21 \text { ) }\end{array}$ & $\begin{array}{l}\text { AF-free group }(\mathrm{n}= \\
15)\end{array}$ & $\begin{array}{l}\text { Normal values from the } \\
\text { literature }\end{array}$ & $\begin{array}{c}\text { Reference } \\
\text { number }\end{array}$ \\
\hline \multicolumn{6}{|c|}{ Clinical characteristics } \\
\hline Age (yrs) & $57.4 \pm 8.9$ & $59.6 \pm 5.8$ & $54.2 \pm 11.5$ & - & - \\
\hline $\begin{array}{l}\text { Duration of AF } \\
\text { (yrs) }\end{array}$ & $6.7 \pm 7.3$ & $8.8 \pm 8.7$ & $3.8 \pm 3.3^{*}$ & - & - \\
\hline Male (\%) & $26(72 \%)$ & $13(62 \%)$ & $13(87 \%)$ & - & - \\
\hline $\begin{array}{l}\text { Hypertension } \\
\text { (\%) }\end{array}$ & $27(75 \%)$ & $15(71 \%)$ & $12(80 \%)$ & - & - \\
\hline Obesity (\%) & $10(28 \%)$ & $3(14 \%)$ & $7(47 \%)$ & - & - \\
\hline Ischaemic HD & $4(11 \%)$ & $3(14 \%)$ & $1(7 \%)$ & - & - \\
\hline \multicolumn{6}{|c|}{ Echocardiographic characteristics } \\
\hline LV EF (\%) & $63 \pm 5$ & $64 \pm 5$ & $62 \pm 6$ & $\geq 55 \%$ & {$[19]$} \\
\hline $\mathrm{LAV}_{\max }(\mathrm{ml})$ & $71 \pm 21$ & $73 \pm 23$ & $67 \pm 20$ & $<56$ & {$[19]$} \\
\hline LAVI $\left(\mathrm{ml} / \mathrm{m}^{2}\right)$ & $34 \pm 10$ & $35 \pm 10$ & $33 \pm 9$ & $<29$ & {$[19]$} \\
\hline $\mathrm{LAV}_{\min }(\mathrm{ml})$ & $36 \pm 17$ & $38+19$ & $30 \pm 12$ & $25 \pm 13$ & [24] \\
\hline $\begin{array}{l}\text { LA SI diam } \\
(\mathrm{mm})\end{array}$ & $55 \pm 5$ & $55 \pm 5$ & $54 \pm 6$ & - & - \\
\hline LAEF (\%) & $51 \pm 10$ & $48 \pm 11$ & $55 \pm 8^{*}$ & $56 \pm 8$ & [24] \\
\hline LAFF (\%) & $35 \pm 7$ & $36 \pm 7$ & $34 \pm 7$ & $41 \pm 14$ & [24] \\
\hline PVSF (\%) & $59 \pm 8$ & $58 \pm 9$ & $60 \pm 7$ & $60 \pm 9$ & {$[25]$} \\
\hline$A a_{\text {lat }}(\mathrm{cm} / \mathrm{s})$ & $10.1 \pm 2.3$ & $9.7 \pm 2$ & $10.7 \pm 2.7$ & - & - \\
\hline$A a_{\text {sept }}(\mathrm{cm} / \mathrm{s})$ & $9.1 \pm 2$ & $8.8 \pm 1.8$ & $9.7 \pm 2.1$ & - & - \\
\hline $\mathrm{Ea}_{\text {lat }}(\mathrm{cm} / \mathrm{s})$ & $11.1 \pm 2.8$ & $11.2 \pm 2.4$ & $10.9 \pm 3.2$ & $>10$ & [23] \\
\hline $\mathrm{Ea}_{\text {sept }}(\mathrm{cm} / \mathrm{s})$ & $8.4 \pm 2.3$ & $8.1 \pm 1.9$ & $8.8 \pm 2.8$ & $>8$ & [23] \\
\hline $\mathrm{E} / \mathrm{Ea}_{\mathrm{avg}}$ & $7.3 \pm 2$ & $7.2 \pm 1.8$ & $7.3 \pm 2.1$ & $<8$ & [23] \\
\hline
\end{tabular}

*: $p<0.05$, recurrent vs AF-free group

Abbreviations:

$A a_{\text {lati }}$ late diastolic velocity measured by pulsed-wave tissue Doppler echocardiography at the lateral mitral annulus

$A a_{\text {septi }}$ late diastolic velocity measured by pulsed-wave tissue Doppler echocardiography at the septal mitral annulus

$A F$; atrial fibrillation

$E$; early diastolic velocity of mitral pulsed wave Doppler inflow

$E a_{a v g}$; average value of septal and lateral early diastolic velocities measured by pulsed-wave tissue Doppler echocardiography

$E a_{\text {lati }}$ early diastolic velocity measured by pulsed-wave tissue Doppler echocardiography at the lateral mitral annulus

$E a_{\text {septi }}$ early diastolic velocity measured by pulsed-wave tissue Doppler echocardiography at the septal mitral annulus

$E F$; ejection fraction $H D$; heart disease

LAEF; left atrial total emptying fraction

$L A F F$; left atrial filling fraction

$L A V$; left atrial volume

$L A V I$; left atrial volume index

$L A V_{\text {maxi }}$ left atrial maximal volume

$L A V_{\text {mini }}$ left atrial minimal volume

$L V$; left ventricular

PVSF; systolic fraction of pulmonary venous flow 
pump function were not significantly different between the recurrent and AF-free groups. However, the left atrial reservoir function by left atrial total emptying fraction was significantly lower in the recurrent group (55 \pm 8 vs $48 \pm 11 \%, p<0.05$ ) (Table 1 ).

\section{Follow-up results}

\section{Left atrial size}

In the recurrent group, at 12 months after ablation, the minimal left atrial volume $(38 \pm 19$ to $44 \pm 20 \mathrm{ml} ; p<$ $0.05)$, the maximal left atrial volume (73 \pm 23 to $81 \pm$ $24 \mathrm{ml} ; p<0.05)$, LAVI $\left(35 \pm 10\right.$ to $39 \pm 11 \mathrm{ml} / \mathrm{m}^{2} ; p=$ 0.01 ) and the maximal left atrial longitudinal diameter (55 \pm 5 to $59 \pm 6 \mathrm{~mm} ; p<0.01$ ) had all increased (Figure 1). In contrast, after successful cryoballoon ablation, LA size had not increased (Table 2).

\section{Left atrial function}

In the recurrent group, at 12 months after ablation, the left atrial reservoir function as assessed by the systolic fraction of pulmonary venous flow (58 \pm 9 to $50 \pm 10 \%$; $p=0.01$ ) and LA pump function assessed by left atrial filling fraction ( $36 \pm 7$ to $33 \pm 8 \% ; p=0.03$ ) had decreased (Figure 2). Left atrial total emptying fraction, which is a parameter of LA reservoir function, did not change significantly during the follow-up; however, it was significantly lower at all follow-up visits in the recurrent group (Figure 3).

In contrast, after successful cryoballoon ablation, LA function had not declined (Table 2).

\section{Left ventricular diastolic function}

Lateral and septal early diastolic velocities did not change significantly during the follow-up (Table 2). Whereas, E/Eaaverage, which was used to assess the mean LV filling pressure, was increased at one year from baseline values $(7.2 \pm 1.8$ to $8.5 \pm 2.3 ; p=0.005)$ (Figure 4).

\section{Discussion}

Our study was the first in which left atrial structural and functional remodeling were examined in detail in patients who had cryoballoon catheter ablation for paroxysmal atrial fibrillation. Successful ablation prevented progressive LA remodeling, whereas the left atrium enlarged in patients with recurrent atrial arrhythmias.

\section{Left atrial size before ablation}

In the present study, left atrial size before cryoballoon ablation did not affect the success rate; there was no difference in LA size before ablation between AF- free and recurrent group of patients. These results are similar to a study by Rodrigues et al. [26] in which PAF patients underwent radiofrequency catheter ablation and the LA volume before ablation was not different between the successful and unsuccessful groups. However, in some other studies LA enlargement before treatment, detected by different imaging modalities has been identified as a risk factor for AF recurrence after radiofrequency catheter ablation [13,27-30].

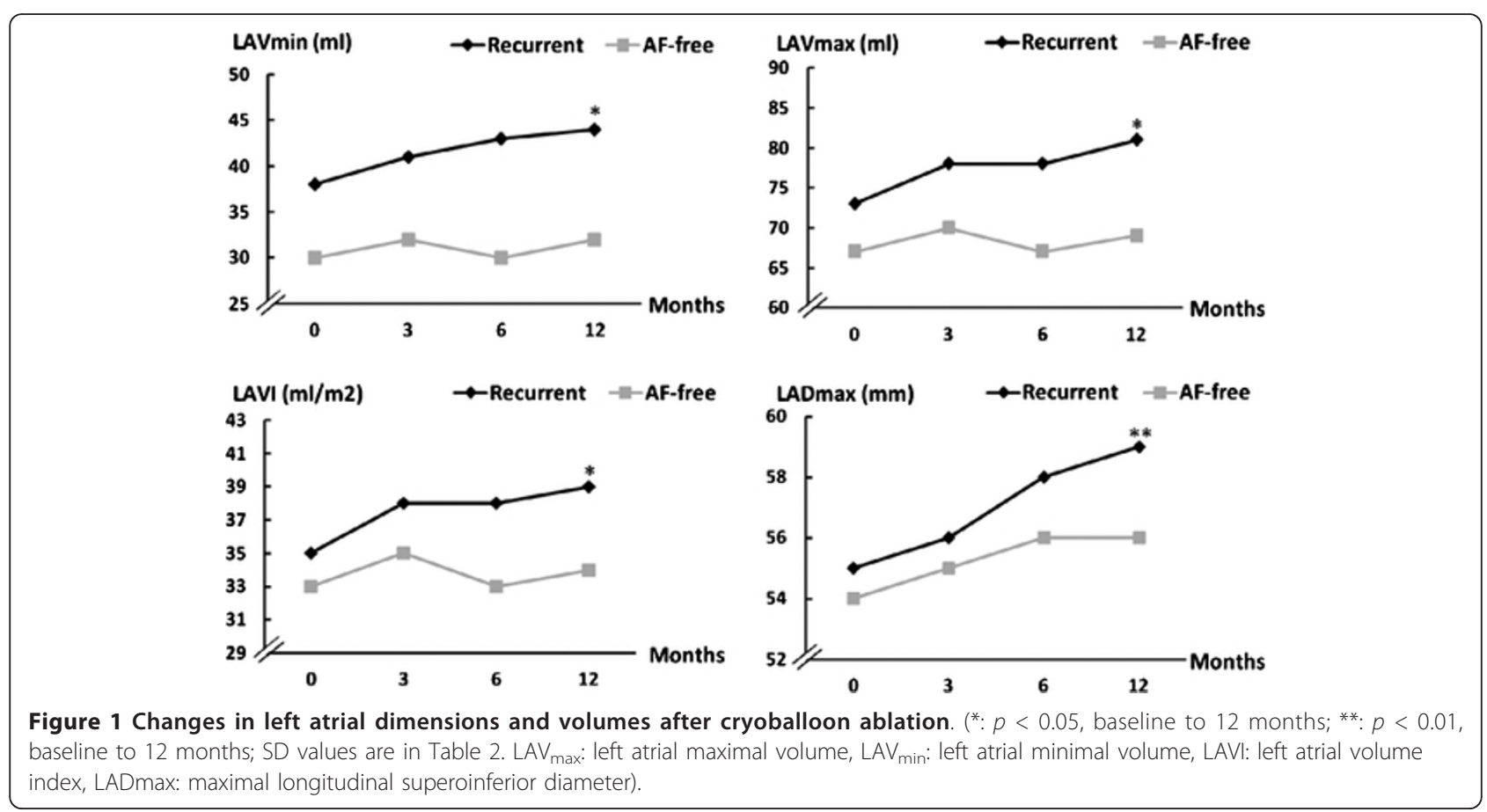


Table 2 Follow-up results

\begin{tabular}{|c|c|c|c|c|c|c|c|c|}
\hline & \multicolumn{4}{|c|}{ Recurrent } & \multicolumn{4}{|c|}{ AF-free } \\
\hline & Baseline & 3 & 6 & 12 & Baseline & 3 & 6 & 12 \\
\hline $\mathrm{LAV}_{\min }(\mathrm{ml})$ & $38 \pm 19$ & $41 \pm 16$ & $43 \pm 18$ & $44 \pm 20^{a}$ & $30 \pm 12$ & $32 \pm 13$ & $30 \pm 11$ & $32 \pm 11$ \\
\hline $\mathrm{LAV}_{\max }(\mathrm{ml})$ & $73 \pm 23$ & $78 \pm 29$ & $78 \pm 23$ & $81 \pm 24^{\mathrm{a}}$ & $67 \pm 20$ & $70 \pm 20$ & $67 \pm 19$ & $69 \pm 15$ \\
\hline LAVI $\left(\mathrm{ml} / \mathrm{m}^{2}\right)$ & $35 \pm 10$ & $38 \pm 13$ & $38+10$ & $39 \pm 11^{a}$ & $33 \pm 9$ & $35 \pm 8$ & $33 \pm 8$ & $34 \pm 7$ \\
\hline $\mathrm{LAD}_{\max }(\mathrm{mm})$ & $55 \pm 5$ & $56 \pm 6$ & $58 \pm 6$ & $59 \pm 6^{b}$ & $54 \pm 6$ & $55 \pm 5$ & $56 \pm 4$ & $56 \pm 5$ \\
\hline LAFF (\%) & $36 \pm 7$ & $35 \pm 8$ & $34 \pm 6$ & $33 \pm 8^{\mathrm{a}}$ & $34 \pm 7$ & $35 \pm 11$ & $38+11$ & $32 \pm 8$ \\
\hline$A a_{\text {sept }}(\mathrm{cm} / \mathrm{s})$ & $8.8 \pm 1.8$ & $8.3 \pm 2.1$ & $8.6 \pm 1.8$ & $8.8 \pm 2.2$ & $9.7 \pm 2.1$ & $10.3 \pm 3.1^{c}$ & $10.4 \pm 1.7^{c}$ & $9.7 \pm 2.1$ \\
\hline$A a_{\text {lat }}(\mathrm{cm} / \mathrm{s})$ & $9.8 \pm 2.1$ & $10.1 \pm 3.4$ & $10.2 \pm 2.7$ & $10.2 \pm 2.7$ & $10.7 \pm 2.7$ & $10.7 \pm 2.2$ & $11.5 \pm 2.1$ & $10.8 \pm 3.1$ \\
\hline LAEF (\%) & $48 \pm 11$ & $47 \pm 13$ & $45 \pm 10$ & $47 \pm 11$ & $55 \pm 8^{c}$ & $55 \pm 8^{c}$ & $56 \pm 8^{d}$ & $55 \pm 9^{c}$ \\
\hline PVSF (\%) & $58 \pm 9$ & $55 \pm 8$ & $55 \pm 9$ & $50 \pm 10^{a}$ & $60 \pm 7$ & $56 \pm 9$ & $61 \pm 9$ & $60 \pm 10$ \\
\hline $\mathrm{Ea}_{\text {sept }}(\mathrm{cm} / \mathrm{s})$ & $8.1 \pm 1.9$ & $8.8 \pm 1.6$ & $8.9 \pm 1.9$ & $7.7 \pm 1$ & $8.8 \pm 2.8$ & $9 \pm 2.5$ & $8.6 \pm 2.3$ & $8.8 \pm 2.3$ \\
\hline $\mathrm{Ea}_{\text {lat }}(\mathrm{cm} / \mathrm{s})$ & $11.2 \pm 2.4$ & $12 \pm 2.5$ & $12 \pm 2.8$ & $11.3 \pm 1.6$ & $10.9 \pm 3.2$ & $11.6 \pm 3.5$ & $11.6 \pm 3.6$ & $11.7 \pm 3.1$ \\
\hline $\bar{E} / \mathrm{Ea}_{\mathrm{avg}}$ & $7.2 \pm 1.8$ & $7.3 \pm 2$ & $8 \pm 2.6$ & $8.5 \pm 2.3^{b}$ & $7.3 \pm 2.1$ & $7.4 \pm 2$ & $7 \pm 1.5$ & $7.4 \pm 2.4$ \\
\hline
\end{tabular}

a: $p<0.05$, baseline to 12 months;

b: $p<0.01$, baseline to 12 months;

c: $p<0.05$, recurrent vs AF-free at the same follow-up visit;

$\mathrm{d}_{\text {: }} p<0.01$, recurrent vs AF-free at the same follow-up visit.

Abbreviations:

Aal $_{\text {at; }}$ late diastolic velocity measured by pulsed-wave tissue Doppler echocardiography at the lateral mitral annulus

$A a_{\text {septi }}$ late diastolic velocity measured by pulsed-wave tissue Doppler echocardiography at the septal mitral annulus

E; early diastolic velocity of mitral pulsed wave Doppler inflow

$E a_{\text {avg; }}$ average value of septal and lateral early diastolic velocities measured by pulsed-wave tissue Doppler echocardiography

$E a_{\text {lati }}$ early diastolic velocity measured by pulsed-wave tissue Doppler echocardiography at the lateral mitral annulus

$E a_{\text {septi }}$ early diastolic velocity measured by pulsed-wave tissue Doppler echocardiography at the septal mitral annulus

$L A D_{\text {max }}$ maximal left atrial longitudinal diameter

$\angle A E F$; left atrial total emptying fraction

$L A F F$; left atrial filling fraction

$L A V I$; left atrial volume index

$L A V_{\text {max }}$ left atrial maximal volume

$L A V_{\text {mini }}$ left atrial minimal volume

PVSF; systolic fraction of pulmonary venous flow

\section{Left atrial structural remodeling}

We found that at one year after unsuccessful cryoballoon catheter ablation left atrial size had increased. In contrast, successful ablation had prevented progressive LA dilatation. The meta-analysis of 17 studies by Jeevanantham et al. [14] confirmed that in patients who had successful radiofrequency catheter ablation of paroxysmal and/or persistent atrial fibrillation LA diameter and volume decreased, which is described as LA structural reverse remodeling. After unsuccessful ablation, LA size did not change or non-significantly increased.

In patients with PAF, LA structural reverse remodeling has not always been observed even after successful catheter ablation. Beukema et al. [8] found that at six months left atrial anteroposterior and superoinferior diameters had decreased in patients who remained in sinus rhythm. Donal et al. [31] investigated 31 lone PAF patients after successful RF ablation, and at 1 year also

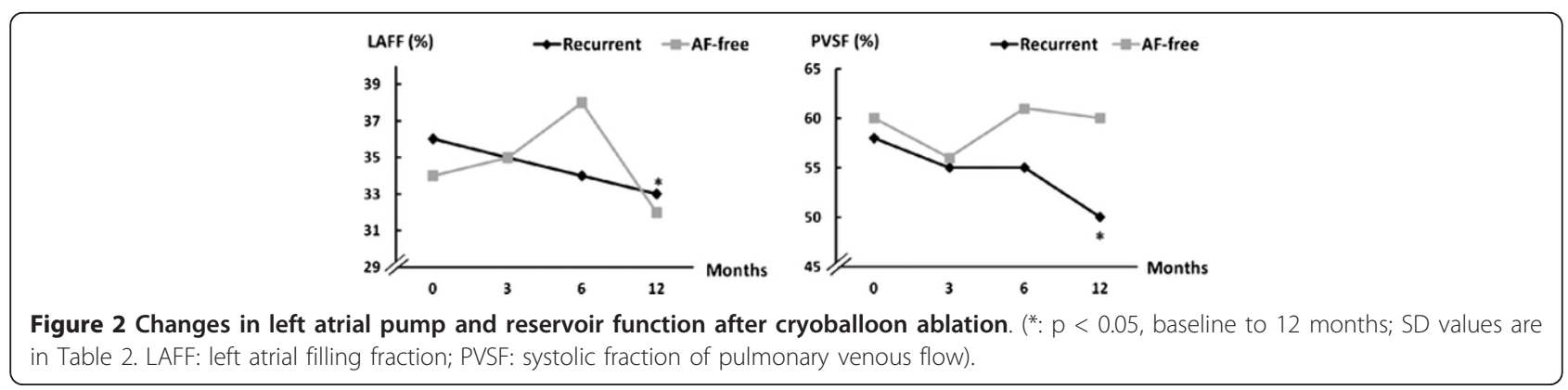




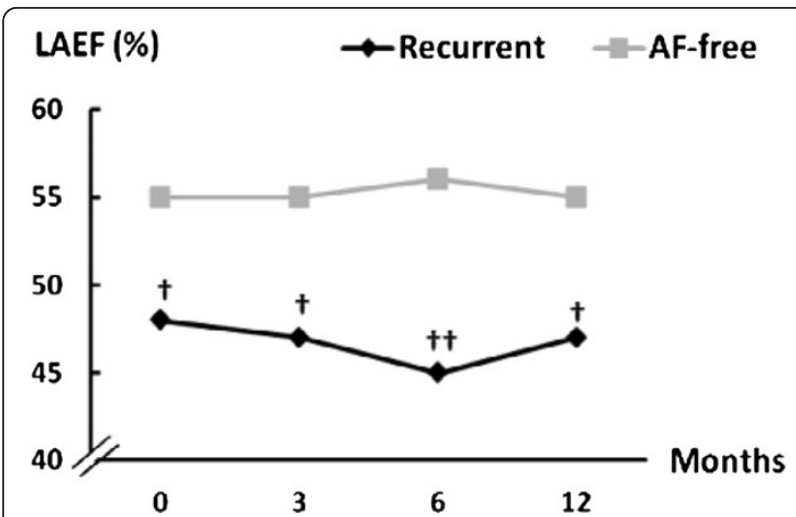

Figure 3 Left atrial total emptying fraction (LAEF) during the follow-up. (t: $p<0.05$, recurrent vs AF-free at the same follow-up visit; †t: $p<0.01$, recurrent vs AF-free at the same follow-up visit; SD values are in Table 2).

found a reduced mean left atrial anteroposterior diameter and LA volume index. Reant et al. observed that LA area had decreased in lone PAF patients 11 months after successful RF ablation; but LA area had also decreased after unsuccessful ablation [6]. Rodrigues [26] et al. observed that after radiofrequency catheter ablation of PAF, there was no significant change of the LA maximal volume $8 \pm 2$ months after ablation, either in the successful, or in the unsuccessfully treated groups. In their study the prevalence of hypertension was 39\%. In our study the high prevalence of associated hypertension $(80 \%)$, which is a well-known determinant of left atrial size, and the limited sample size (AF-free group: $\mathrm{N}=15$ ), probably contributed to the lack of reverse remodeling. Another potential explanation could be that the left atrium of the AF-free patients might have been remodeled to such an extent during the years in which they had paroxysmal atrial fibrillation (3.8 \pm 3.3 years), that the one-year follow-up period was not long enough for significant reverse remodeling which could be

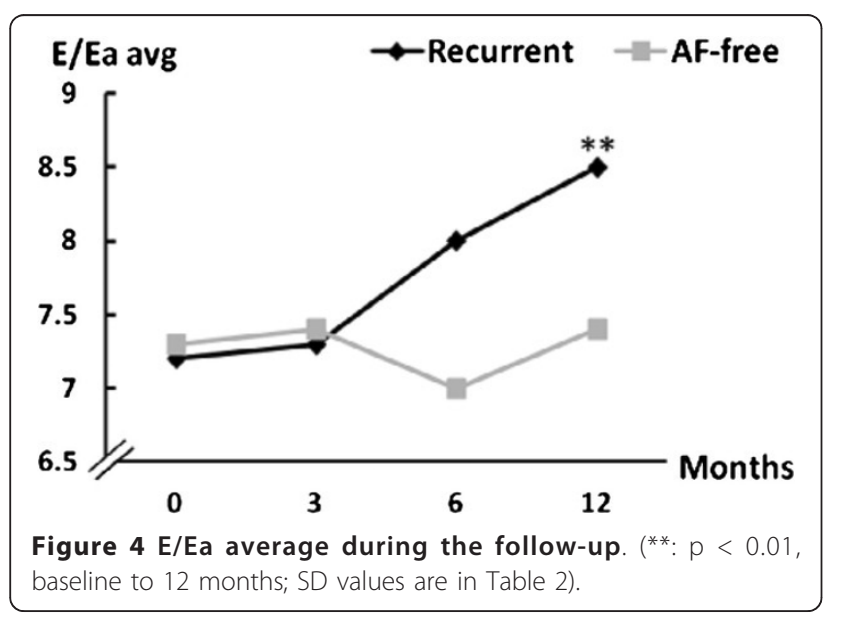

recognised by two-dimensional transthoracic echocardiography, especially in such a small sample (AF-free group: $\mathrm{N}=15$ ).

\section{Left atrial functional remodeling Left atrial booster pump function}

In our study the left atrial filling fraction-a parameter of LA pump function-decreased 12 months after ablation in the recurrent group. After successful cryoballoon ablation, LA pump function did not change.

In previous studies, after successful radiofrequency ablation in patients with paroxysmal and/or persistent AF, LA pump functional parameters, such as LA filling fraction [6,11], and TDE derived Aa [32] were found to improve.

In PAF patients who underwent successful radiofrequency catheter ablation, similarly to our study, Aa velocities did not change in a study by Rodrigues et al. $8 \pm 2$ month after RFCA [26]. In studies by Reant et al. [6,7], neither Aa velocities, nor LAFF changed 12 months after successful RFCA. Whereas, Donal et al. found an increase of Aa velocity one year after successful ablation [31], in addition to an increase in the more sophisticated LA pump functional parameter of end-diastolic strain rate.

\section{Left atrial reservoir function}

In our study the left atrial total emptying fraction-a variable of left atrial reservoir function-was lower at baseline and during follow-up in the recurrent group, but it did not change in either group.

After 12 months the pulmonary venous systolic fraction-a parameter of LA reservoir function-decreased in the recurrent group. After successful cryoballoon ablation, it did not change. In other studies $[6,33]$ as confirmed by a meta-analysis [14] LA reservoir function, assessed by LA total emptying fraction, declined in patients whose arrhythmia recurred.

In PAF patients who underwent successful radiofrequency catheter ablation, left atrial total emptying fraction did not change significantly after 8 months [26] or one year in another studies [6,7]. However, improving LA compliance was shown by Donal et al. a year after successful ablation by increasing LA lateral strain and systolic strain rate [31].

\section{Left ventricular diastolic function before and after ablation}

Left ventricular diastolic function did not affect the success rate in the present study; no difference was found between the groups regarding LV diastolic function at baseline.

We did not demonstrate any change in Ea velocities during the one-year follow-up in the recurrent, or in the AF-free group, similarly to the study of patients with 
successful PAF ablation by Donal et al. [31]. However, in the studies by Reant et al. [6,7] Ea was found to increase following successful radiofrequency catheter ablation in PAF patients during a 11-month follow-up.

In our study the E/Eaaverage was increased at one year after cryoballoon catheter ablation in the recurrent group. E/Ea ratio was shown to decrease [6,7] or did not change [31] in other studies after successful radiofrequency catheter ablation in PAF patients

\section{Limitations}

The number of patients in our study was relatively small, similar to other studies of this topic $[6,7,26]$; but we studied a very homogeneous population of patients with exclusively paroxysmal, nonvalvular atrial fibrillation and with normal left ventricular ejection fraction.

The post-procedure monitoring of AF recurrences was fairly intensive in our present study; but it may have missed asymptomatic recurrences.

We used 2DE to calculate LAV, while measurements with magnetic resonance imaging (MRI) or multislice computerized tomography (CT) are more accurate: all echocardiographic methods systematically underestimate LAV [34,35]. However, acquisition of MRI images is time consuming, and the use of multislice CT requires contrast agents and high radiation exposure. In addition, follow-up studies with MRI or CT would be very costly. 2DE methods are safe, widely available, inexpensive, feasible and reliable both for research purposes and clinical practice, especially during follow-up [36]. During longterm monitoring of left atrial remodelling, echocardiography might be useful to detect the chronic consequences of both symptomatic and silent recurrent atrial arrhythmias.

Several approaches are used to measure LAV by $2 \mathrm{DE}$, which makes the comparison of our data with other studies more challenging. LA volumes measured in our study seemed to be larger than some other studies $[37,38]$, which perhaps influenced the success rate during follow-up which was the bottom of the normal range known from the literature [15].

Usually, 20 to $30 \%$ of the patients with clinically unsuccessful ablation undergo a redo procedure. According to the definition of the Ablation Consensus Statement [4] in our study only those 13 patients were clinically unsuccessful who had recurrent arrhythmia after the first 3-month blanking period. In that group during the one-year follow-up period there was no redo ablation, mainly because of the limited availability and costs of the procedure. After the one-year follow-up period, 5 out of the 13 unsuccessful patients (38\%) underwent a repeat ablation procedure (by radiofrequency catheter ablation).

\section{Conclusions}

In patients whose nonvalvular paroxysmal atrial fibrillation recurred within one year after cryoballoon catheter ablation, left atrial size increased, left atrial pump and reservoir function declined, and the left ventricular filling pressure increased, all related to left atrial remodeling (progressive enlargement). In contrast, successful cryoballoon catheter ablation prevented progressive left atrial remodeling.

It would have been interesting to compare the effect of cryoballoon catheter ablation and RFCA on the LA remodeling which can be subject of a further study.

\section{Abbreviations}

2DE: Two-dimensional echocardiography; A: Late diastolic velocity of mitral pulsed wave Doppler inflow; $A_{1}$ : Left atrial area from apical four-chamber view; $A_{2}$ : Left atrial area from apical two-chamber view; Aalat: Late diastolic velocity measured by pulsed-wave tissue Doppler echocardiography at the lateral mitral annulus; $\mathrm{Aa}_{\text {sept: }}$ Late diastolic velocity measured by pulsed-wave tissue Doppler echocardiography at the septal mitral annulus; AF: Atrial fibrillation; CCA: Cryoballoon catheter ablation; $\mathrm{CHADS}_{2}$-score: Congestive heart failure; hypertension; age; diabetes mellitus; stroke; CT: Computed tomography; D: Diastolic velocity of pulmonary venous flow; DT: Deceleration time; E: Early diastolic velocity of mitral pulsed wave Doppler inflow; $\mathrm{Ea}_{\text {avg: }}$ : Average value of septal and lateral early diastolic velocities measured by pulsed-wave tissue Doppler echocardiography; Ealat: Early diastolic velocity measured by pulsed-wave tissue Doppler echocardiography at the lateral mitral annulus; Ea $a_{\text {sept: }}$ Early diastolic velocity measured by pulsed-wave tissue Doppler echocardiography at the septal mitral annulus; EF: Ejection fraction; LA: Left atrium; LAFF: Left atrial filling fraction; LAEF: Left atrial total emptying fraction; LAV: Left atrial volume; LAV max: Left atrial maximal volume; $L A V_{\text {min }}$ : Left atrial minimal volume; $L A V I$ : Left atrial volume index; LV: Left ventricular; MRI: Magnetic resonance imaging; PAF: Paroxysmal atrial fibrillation; PVSF: Systolic fraction of pulmonary venous flow; RFCA: Radiofrequency catheter ablation; S: Systolic velocity of pulmonary venous flow; SD: Standard deviation; TDE: Tissue Doppler echocardiography; VTI: Velocity time integral.

\section{Acknowledgements}

The corresponding author is very grateful to his tutor, Professor Maria Lengyel (1938-2010), for her help and encouragement during this study. The authors wish to thank Prof Alan Fraser for his helpful advice about the revision of this manuscript.

TE was funded by a full-time Ph.D. scholarship of Semmelweis University, School of Ph.D. Studies, Budapest, Hungary.

\section{Author details}

'Semmelweis University, School of Ph.D. Studies, Budapest, Üllỏi út 26 H1085, Hungary. ${ }^{2}$ Gottsegen Hungarian Institute of Cardiology, Budapest, Haller utca 29 H-1096, Hungary.

\section{Authors' contributions}

ML and TE introduced the study idea. AK, AM, CF made substantial contributions to study conception and design, and performed the ablations. TE acquired the transthoracic echocardiography images, performed the analysis and wrote the manuscript. AT acquired the transoesophageal echocardiography images and reviewed and helped to revise the manuscript. MD helped in the interpretation of the results and statistical analysis. All authors read and approved the final manuscript.

\section{Competing interests}

The authors declare that they have no competing interests.

Received: 24 November 2011 Accepted: 19 March 2012 Published: 19 March 2012 


\section{References}

1. Sanfilippo AJ, Abascal VM, Sheehan M, Oertel LB, Harrigan P, Hughes RA Weyman AE: Atrial enlargement as a consequence of atrial fibrillation. A prospective echocardiographic study. Circulation 1990, 82:792-797.

2. Boldt A, Wetzel U, Lauschke J, Weigl J, Gummert J, Hindricks G, Kottkamp H, Dhein S: Fibrosis in left atrial tissue of patients with atrial fibrillation with and without underlying mitral valve disease. Heart 2004, 90:400-405.

3. Douglas PS: The left atrium: a biomarker of chronic diastolic dysfunction and cardiovascular disease risk. J Am Coll Cardiol 2003, 42:1206-1207.

4. Calkins H, Brugada J, Packer DL, Cappato R, Chen SA, Crijns HJ, Damiano RJ Jr, Davies DW, Haines DE, Haissaguerre M, lesaka Y, Jackman W, Jais P, Kottkamp H, Kuck KH, Lindsay BD, Marchlinski FE, McCarthy PM, Mont JL, Morady F, Nademanee K, Natale A, Pappone C, Prystowsky E, Raviele A, Ruskin JN, Shemin RJ, Heart Rhythm Society, European Heart Rhythm Association, European Cardiac Arrhythmia Society American College of Cardiology American Heart Association Society of Thoracic Surgeons: HRS/ EHRA/ECAS expert consensus statement on catheter and surgical ablation of atrial fibrillation: recommendations for personnel, policy, procedures and follow-up a report of the Heart Rhythm Society (HRS) Task Force on Catheter and Surgical Ablation of Atrial Fibrillation. Europace 2007, 9:335-379.

5. European Heart Rhythm Association, European Association for CardioThoracic Surgery, Camm AJ, Kirchhof P, Lip GY, Schotten U, Savelieva I, Ernst S, Van Gelder IC, Al-Attar N, Hindricks G, Prendergast B, Heidbuchel H, Alfieri O, Angelini A, Atar D, Colonna P, De Caterina R, De Sutter J, Goette A, Gorenek B, Heldal M, Hohloser SH, Kolh P, Le Heuzey JY, Ponikowski P, Rutten FH, ESC Committee for Practice Guidelines, Vahanian A, Auricchio A, Bax J, Ceconi C, Dean V, Filippatos G, et al: Guidelines for the management of atrial fibrillation: the Task Force for the Management of Atrial Fibrillation of the European Society of Cardiology (ESC). Europace 2010, 12:1360-1420.

6. Reant $P$, Lafitte $S$, Jaïs $P$, Serri $K$, Weerasooriya $R$, Hocini M, Pillois $X$, Clementy J, Haïssaguerre $M$, Roudaut R: Reverse remodeling of the left cardiac chambers after catheter ablation after 1 year in a series of patients with isolated atrial fibrillation. Circulation 2005, 112:2896-2903.

7. Reant $\mathrm{P}$, Lafitte $\mathrm{S}$, Bougteb $\mathrm{H}$, Sacher $\mathrm{F}$, Mignot $\mathrm{A}$, Douard $\mathrm{H}$, Blanc $\mathrm{P}$, Hocini M, Clementy J, Haissaguerre M, Roudaut R, Jais P: Effect of catheter ablation for isolated paroxysmal atrial fibrillation on longitudinal and circumferential left ventricular systolic function. Am J Cardiol 2009, 103:232-237.

8. Beukema WP, Elvan A, Sie HT, Misier AR, Wellens HJ: Successful radiofrequency ablation in patients with previous atrial fibrillation results in a significant decrease in left atrial size. Circulation 2005, 112:2089-2095.

9. Tops LF, Bax JJ, Zeppenfeld K, Jongbloed MR, van der Wall EE, Schalij MJ: Effect of radiofrequency catheter ablation for atrial fibrillation on left atrial cavity size. Am J Cardiol 2006, 97:1220-1222.

10. Verma A, Kilicaslan F, Adams JR, Hao S, Beheiry S, Minor S, Ozduran V, Claude Elayi S, Martin DO, Schweikert RA, Saliba W, Thomas JD, Garcia M, Klein A, Natale A: Extensive ablation during pulmonary vein antrum isolation has no adveres impact on left atrial function: an echocardiography and cine computed tomography analysis. J Cardiovasc Electrophysiol 2006, 17:741-746.

11. Takahashi $Y, O^{\prime}$ Neill MD, Hocini $M$, Reant $P$, Jonsson $A$, Jaïs $P$, Sanders $P$, Rostock T, Rotter M, Sacher F, Laffite S, Roudaut R, Clémenty J, Haïssaguerre M: Effects of stepwise ablation of chronic atrial fibrillation on atrial electrical and mechanical properties. J Am Coll Cardiol 2007, 49:1306-1314.

12. Müller H, Noble $S$, Keller PF, Sigaud P, Gentil $P$, Lerch $R$, Shah D, Burri H: Biatrial anatomical reverse remodeling after radiofrequency catheter ablation for atrial fibrillation: evidence from real-time three-dimensional echocardiography. Europace 2008, 10:1073-1078.

13. Marsan NA, Tops LF, Holman ER, Van de Veire NR, Zeppenfeld K, Boersma E, van der Wall EE, Schalij MJ, Bax JJ: Comparison of left atrial volumes and function by real-time three-dimensional echocardiography in patients having catheter ablation for atrial fibrillation with persistence of sinus rhythm versus recurrent atrial fibrillation three months later. Am J Cardiol 2008, 102:847-853.

14. Jeevanantham V, Ntim W, Navaneethan SD, Shah S, Johnson AC, Hall B, Shah A, Hundley WG, Daubert JP, Fitzgerald D: Meta-analysis of the effect of radiofrequency catheter ablation on left atrial size, volumes and function in patients with atrial fibrillation. Am J Cardiol 2010, 105:1317-1326.

15. Andrade JG, Khairy P, Guerra PG, Deyell MW, Rivard L, Macle L, Thibault B, Talajic M, Roy D, Dubuc M: Efficacy and safety of cryoballoon ablation for atrial fibrillation: a systematic review of published studies. Hear Rhythm 2011, 8:1444-1451.

16. Ozcan C, Ruskin J, Mansour M: Cryoballoon catheter ablation in atrial fibrillation. Cardiol Res Pract 2011, 2011-256347.

17. Földesi C, Kardos A, Mihálcz A, Som Z, Hódi G, Andréka P, Szili-Török T: New method for the treatment of atrial fibrillation: circumferential cryoballoon ablation of the pulmonary vein. Orv Hetil 2008, 149:1779-1784

18. Fuster V, Rydén LE, Cannom DS, Crijns HJ, Curtis AB, Ellenbogen KA, Halperin JL, Le Heuzey JY, Kay GN, Lowe JE, Olsson SB, Prystowsky EN, Tamargo JL, Wann S, Task Force on Practice Guidelines, American College of Cardiology/American Heart Association, Committee for Practice Guidelines, European Society of Cardiology, European Heart Rhythm Association Heart Rhythm Society: ACC/AHA/ESC 2006 guidelines for the management of patients with atrial fibrillation-executive summary: a report of the American College of Cardiology/American Heart Association Task Force on Practice Guidelines and the European Society of Cardiology Committee for Practice Guidelines (writing committee to revise the 2001 Guidelines for the Management of Patients with Atrial Fibrillation). Eur Heart J 2006, 16:1979-2030.

19. Lang RM, Bierig M, Devereux RB, Flachskampf FA, Foster E, Pellikka PA Picard MH, Roman MJ, Seward J, Shanewise JS, Solomon SD, Spencer KT, Sutton MS, Stewart WJ: Recommendations for chamber quantification: a report from the American Society of Echocardiography's Guidelines and Standards Committee and the Chamber Quantification Writing Group, developed in conjunction with the European Association of Echocardiography, a branch of the European Society of Cardiology. J Am Soc Echocardiogr 2005, 18:1440-1463.

20. Leung DY, Boyd A, Ng AA, Chi C, Thomas L: Echocardiographic evaluation of left atrial size and function: current understanding, pathophysiologic correlates, and prognostic implications. Am Heart J 2008, 156:1056-1064

21. Blume GG, Mcleod CJ, Barnes ME, Seward JB, Pellikka PA, Bastiansen PM, Tsang TS: Left atrial function: physiology, assessment, and clinical implications. Eur J Echocardiogr 2011, 12:421-430.

22. Paulus WJ, Tschöpe C, Sanderson JE, Rusconi C, Flachskampf FA, Rademakers FE, Marino P, Smiseth OA, De Keulenaer G, Leite-Moreira AF Borbély A, Edes I, Handoko ML, Heymans S, Pezzali N, Pieske B, Dickstein K, Fraser AG, Brutsaert DL: How to diagnose diastolic heart failure: a consensus statement on the diagnosis of heart failure with normal left ventricular ejection fraction by the Heart Failure and Echocardiography Associations of the European Society of Cardiology. Eur Heart J 2007, 28:2539-2550.

23. Nagueh SF, Appleton CP, Gillebert TC, Marino PN, Oh JK, Smiseth OA, Waggoner AD, Flachskampf FA, Pellikka PA, Evangelisa A: Recommendations for the evaluation of left ventricular diastolic function by echocardiography. Eur J Echocardiogr 2009, 10:165-193.

24. Khankirawatana B, Khankirawatana S, Peterson B, Mahrous H, Porter TR: Peak atrial systolic mitral annular velocity by doppler tissue reliably predicts left atrial systolic function. J Am Soc Echocardiogr 2004, 17:353-360.

25. Thomas L, Thomas SP, Hoy M, Boyd A, Schiller NB, Ross DL: Comparison of left atrial volume and function after linear ablation and after cardioversion for chronic atrial fibrillation. Am J Cardiol 2004, 93:165-170.

26. Rodrigues AC, Scannavacca MI, Caldas MA, Hotta VT, Pisani C, Sosa EA, Mathias W Jr: Left atrial function after ablation for paroxysmal atrial fibrillation. Am J Cardiol 2009, 103:395-398.

27. Abecasis J, Dourado R, Ferreira A, Saraiva C, Cavaco D, Santos KR, Morgado FB, Adragão P, Silva A: Left atrial volume calculated by multidetector computed tomography may predict successful pulmonary vein isolation in catheter ablation of atrial fibrillation. Europace 2009, 11:1289-1294.

28. Shin SH, Park MY, Oh WJ, Hong SJ, Pak HN, Song WH, Lim DS, Kim YH, Shim WJ: Left atrial volume is a predictor of atrial fibrillation recurrence after catheter ablation. J Am Soc Echocardiogr 2008, 21:697-702.

29. Parikh SS, Jons C, McNitt S, Daubert JP, Schwarz KQ, Hall B: Predictive capability of left atrial size measured by $C T$, TEE, and TTE for recurrence 
of atrial fibrillation following radiofrequency catheter ablation. Pacing Clin Electrophysiol 2010, 33:532-540.

30. Montefusco A, Biasco L, Blandino A, Cristoforetti Y, Scaglione M, Caponi D Di Donna P, Boffano C, Cesarani F, Coin D, Perversi J, Gaita F: Left atrial volume at MRI is the main determinant of outcome after pulmonary vein isolation plus linear lesion ablation for paroxysmal-persistent atrial fibrillation. J Cardiovasc Med (Hagerstown) 2010, 11:593-598.

31. Donal E, Ollivier R, Veillard D, Hamonic S, Pavin D, Daubert JC, Mabo P: Left atrial function assessed by trans-thoracic echocardiography in patients treated by ablation for a lone paroxysmal atrial fibrillation. Eur $J$ Echocardiogr 2010, 11:845-852.

32. Choi Jl, Park SM, Park JS, Hong SJ, Pak HN, do Lim S, Kim YH, Shim WJ: Changes in left atrial structure and function after catheter ablation and electrical cardioversion for atrial fibrillation. Circ J 2008, 72:2051-2057.

33. Schneider C, Malisius R, Krause K, Lampe F, Bahlmann E, Boczor S, Antz M, Ernst $S$, Kuck KH: Strain rate imaging for functional quantification of the left atrium: atrial deformation predicts the maintenance of sinus rhythm after catheter ablation of atrial fibrillation. Eur Heart J 2008, 29:1397-1409.

34. Vandenberg BF, Weiss RM, Kinzey J, Acker M, Stark CA, Stanford W, Burns TL, Marcus ML, Kerber RE: Comparison of left atrial volume by twodimensional echocardiography and cine-computed tomography. Am J Cardiol 1995, 75:754-757.

35. Rodevan O, Bjornerheim R, Ljosland M, Maehle J, Smith HJ, Ihlen H: Left atrial volumes assessed by three- and two-dimensional echocardiography compared to MRI estimates. Int I Card Imag 1999, 15:397-410.

36. Lester SJ, Ryan EW, Schiller NB, Foster E: Best method in clinical practice and in research studies to determine left atrial size. Am J Cardiol 1999, 84:829-832.

37. Van Belle Y, Janse P, Rivero-Ayerza MJ, Thornton AS, Jessurun ER, Theuns $D$, Jordaens L: Pulmonary vein isolation using an occluding cryoballoon for circumferential ablation: feasibility, complications, and short-term outcome. Eur Heart J 2007, 28:2231-2237.

38. Linhart M, Bellmann B, Mittmann-Braun E, Schrickel JW, Bitzen A, Andrié R, Yang A, Nickenig G, Lickfett L, Lewalter T: Comparison of cryoballoon and radiofrequency ablation of pulmonary veins in 40 patients with paroxysmal atrial fibrillation: a case-control study. J Cardiovasc Electrophysiol 2009, 20:1343-1348.

doi:10.1186/1476-7120-10-11

Cite this article as: Erdei et al: Could successful cryoballoon ablation of paroxysmal atrial fibrillation prevent progressive left atrial remodeling? Cardiovascular Ultrasound 2012 10:11.

\section{Submit your next manuscript to BioMed Central and take full advantage of:}

- Convenient online submission

- Thorough peer review

- No space constraints or color figure charges

- Immediate publication on acceptance

- Inclusion in PubMed, CAS, Scopus and Google Scholar

- Research which is freely available for redistribution

Submit your manuscript at www.biomedcentral.com/submit
Biomed Central 